\title{
Green Supply Chain Performance Measurement using Fuzzy-ANP based Balanced Scorecard: A Collaborative Decision-Making Approach
}

Arijit Bhattacharya ${ }^{1}$

Prasanta Kumar Dey ${ }^{4}$
Priyabrata Mohapatra ${ }^{2}$

Malcolm Brady 5
Vikas Kumar ${ }^{3 *}$

Manoj Kumar Tiwari ${ }^{6}$

\section{Sai S. Nudurupati ${ }^{7}$}

1, 3, \& ${ }^{5}$ Management Group, Dublin City University Business School, Dublin, Ireland.

E-mails: ${ }^{1}$ arijit.bhattacharya@dcu.ie, ${ }^{3}$ vikas.kumar@dcu.ie, ${ }^{5}$ malcolm.brady@dcu.ie

$2 \& 6$ Dept. of Industrial Engineering and Management, Indian Institute of Technology, Kharagpur, India.

E-mails: ${ }^{2}$ priya.iitkgp@gmail.com, ${ }^{6}$ mktiwari9@iem.iitkgp.ernet.in

${ }^{4}$ Aston Business School, Aston University, Aston Triangle, Birmingham, B4 7ET, UK.

E-mail: ${ }^{4}$ p.k.dey@aston.ac.uk

${ }^{7}$ Business School, Manchester Metropolitan University, M15 6BH, UK.

Email: ${ }^{7}$ s.nudurupati@mmu.ac.uk

* Corresponding author

\begin{abstract}
The purpose of this paper is to delineate a green supply-chain performance measurement framework using an intra-organisational Collaborative Decision-Making (CDM) approach. A fuzzy-Analytic Network Process (ANP) based Green Balanced Scorecard (GrBSc) has been used within the CDM approach. CDM aids in arriving at a consistent, accurate and timely data flow across all cross-functional areas of a business thereby providing real-time information for the evaluation, control and improvement of processes, products and services so as to meet both business objectives and rapidly changing customer needs. A green causal relationship is established and linked to the fuzzy-ANP approach. The causal relationship involves organisational commitment, eco-design, green supply-chain process, social performance and sustainable performance constructs. Subconstructs and sub-sub-constructs are also identified and linked to the causal relationship to form a network. The fuzzy-ANP approach suitably handles the vagueness of the linguistics information of the CDM approach. The CDM approach is implemented in a UK-based carpet manufacturing firm. The performance measurement approach, in addition to the traditional financial performance and accounting measures, aids in making decisions of the firm in regard to the overall organisational goals. The implemented approach assists the firm in identifying further requirements of the collaborative data across the supply-chain and information about customers and markets. Overall, the CDM-based GrBSc approach assists managers in deciding if the suppliers' performances meet the industry and environment standards and the human resource is effective.
\end{abstract}

Keywords: Supply chain; Green balanced scorecard; Fuzzy ANP; Collaborative decisionmaking; Carpet manufacturing industry; Performance measurement.

\section{Introduction}

Supply Chain Management (SCM) has strategic implications for businesses. SCM is one of the most effective operational strategies to enhance organisational competitiveness (Gunasekaran and Cheng 2008). Sustainability of a business in the context of a rapidly 
changing global economy requires identifying performance measures on most of the critical evaluating criteria of the Supply-Chain (SC). Such a procedure considers critical evaluation of the dependent business strategies as an integral part of the business. The traditional SCM model defines the SC performance as the degree of fit between ideal profiles of knowledge elements (i.e., critical evaluating criteria) and business strategies (Hult et al. 2006). In recent times manufacturing operations have been strongly influenced by changing environmental requirements (Beamon 1999). Therefore, adequate attention is required to incorporate green operational strategies in an SC. Effective and efficient green management strategies, when combined with manufacturing operational strategies, facilitate the business in evaluating, managing, enhancing and controlling the individual performances of the manufacturing operations.

Although a good number of studies have been reported in the literature, there is a lack of benchmarked knowledge on the measurement of green performance in SCs (Björklund et al. 2012). Existing performance measurement approaches disregard sustainable development elements, viz., social and green aspects (Cuthbertson and Piotrowicz 2008). Therefore, a thorough investigation into the links between green constructs and sub-constructs of SC is necessitated considering other contributing inter-organisational elements responsible for performance measurement.

In order to bridge the existing gap a Collaborative Decision-Making (CDM) approach has been adopted in this paper. This paper demonstrates how a Green Balanced Scorecard (GrBSc) method is developed and implemented for a UK-based carpet manufacturing company in order to measure SC performance within a CDM environment. The company has systematic plan to reduce waste. Their workers are appropriately trained and educated to 
contribute in the waste reduction process. They have identified eight wastes in manufacturing and implemented methods to reduce those. Additionally, they have invested in training their human resources to implement an effective waste reduction process. The company is currently extending its quality management programs to major critical suppliers.

The intra-organisational CDM supports an efficient information exchange among disparate stakeholders of the carpet manufacturing firm. The firm's stakeholders working together to create technological, managerial and procedural solutions in both the pre- and postmanufacturing processes share knowledge-base that contributes to efficient decision-making. A multi-criteria decision-making tool, fuzzy-Analytic Network Process (ANP) (Saaty 1996), assists in coordinating the various functionalities of the company required to arrive at timely collective decisions, enabling all relevant stakeholders to participate in the process for an effective decision-making process through the design and use of a GrBSc. A synergistic effect of three inter-dependent major functions is considered in this article so as to enable effective green intra-company collaboration and networking thereby forming the basis of the CDM platform. These are: (i) discussion and overlay knowledge (both the subjective and objective), (ii) knowledge sharing and (iii) collective decision for the best course of action.

The paper is organised in the following manner. Section 2 illustrates a comprehensive background based on a systematic literature review. The next section elucidates the GrBSc framework. Section 4 delineates the implementation of GrBSc focusing on a case of a UKbased carpet manufacturing company. Section 5 discusses observations from the implemented approach followed by a discussion. The last section concludes the paper indicating the scope for further research.

\section{Background}


A considerable number of performance measurement approaches exists in the literature (Bhagwat and Sharma 2009; Alfaro et al 2007; Mettänen 2005; Gunasekaran et al. 2004). Key performance indicators (Camarinha-Matos and Abreu 2007) and their measures and metrics in SCM are reported in literature based on a survey and case studies (Gunasekaran and Kobu 2007). Yang (2011) reports a conceptual framework for evaluating the knowledge sharing effect of SC capabilities on SC performance. It is observed that an effective performance measurement approach should consider managerial accounting along with operational strategies. Manufacturing synergy can be developed if a strong link is developed among strategies, operational actions and performance (Ketokivi and Heikkilä 2003). However, gaps between these two disciplines exist within SC research (Hofmann and Locker 2009).

The scope of this paper is limited to green SC performance using a BSc-based CDM approach. Therefore, a critique of the literature in the arena of green-SC performance and BSc-based performance measurement frameworks is relevant.

\subsection{Green supply chain performance}

Significant awareness amongst manufacturers, increased level of societal awareness among consumers and regulatory pressures on businesses are steadily forcing SCs to meet consumer demand for "greener" products (Hitchcock 2012). Therefore, it is envisaged that the organisation performance would take a different shape when green and societal aspects of SCs are considered. The literature on the green SC performance is wide-ranging (Dey and Cheffi 2012; Olugu et al. 2010; Tsoulfas and Pappis 2008). A good level of recognition is found amongst practitioners on the necessity for more knowledge on environmental performance across different actors in an SC (Björklund et al. 2012). Modern SC 
performance measurement includes 'ecological sustainable performance measure' as a component (Bai et al. 2012). Taking into account present challenges and obstacles, a definition of green-SCM is as follows: "to maximise overall environmental profit by adopting a life cycle approach through product design, material selection, manufacturing, and sales and recovery, and therefore helps the firm to realise its sustainable development and improvement" (Shi et al. 2012). Therefore, in addition to economic performance measure (Rao and Holt 2005) it is essential to identify the SC constructs, ecological aspects of performance measures and causal relationships that form the building blocks of these greenSC elements within an organisation.

\subsection{Balanced scorecard and its variants for performance measurement}

The purpose of BSc is to keep balanced the scores of a set of performance measures. The measures comprise short and long-term objectives, financial and non-financial measures, lagging and leading indicators and internal and external performance perspectives (Kaplan and Norton 1992, 1996). Three most relevant ways have been elucidated for utilising a BSc framework in assessing performance (Malmi 2001): (i) to focus on management of the organisation by objectives, (ii) to use as an information system and (iii) to visualise the cause and effect relationships between different measures. Customised forms of BSc have been adopted by many companies (Lee et al. 2008). Businesses are aligned to new strategies thereby opening growth opportunities based on more customised, value-added products and services (Martinsons et al. 1999). Empirical evidence from Dutch firms suggests that appropriate usage of BSc improves performance of the company (Braam and Nijssen 2004). Examples of the application of BSc framework in various sectors for performance measurement are abundant (Mendes et al. 2012; Sawalqa et al. 2011). However, the way of 
BSc implementation plays a crucial role for performance measurement (Braam and Nijssen 2004).

There are instances where multi-criteria methodologies are integrated with the BSc framework. For example, fuzzy Analytic Hierarchy Process (AHP) (Saaty 1980) is integrated with the BSc approach (Lee et al. 2008). Use of AHP and its variants in the BSc framework provides a mechanism for calculating the relative weights for each performance measure $(\mathrm{Wu}$ et al. 2009). Data envelopment analysis, case-based reasoning (Yuan and Chiu 2009) and quality function deployment (Cohen 2011) are useful tools for performance measurement within the BSc framework (Banker et al. 2004). A hypothetical case study using the BSc framework for performance evaluation in the construction sector is reported using AHP and multi-attribute utility theory (Stwart and Mohamed 2001). While AHP is used to structure the hierarchy and relative weightings of performance perspectives, indicators and measures (Lee et al. 2008; Stwart and Mohamed 2001) within the BSc framework it does not consider the interdependencies, using a network, of the causal relationship meant for GrBSc.

Another variant of BSc uses the Analytic Network Process (ANP) for performance evaluation (Ravi et al. 2005). Both AHP and ANP are "versatile multi-attribute decision methodologies" that can be adapted to facilitate the implementation of a wide range of BSc frameworks (Leung et al. 2006). Advantageously ANP considers the interdependencies among criteria, sub-criteria and determinants. Fuzzy ANP-based BSc approaches are reported in Tseng (2010) and Yüksel and Dağdeviren (2010). Interpretive structural modelling and ANP are used in the development of BSc (Thakkar et al. 2006). A sustainability BSc framework is reported using fuzzy Delphi method and ANP (Hsu et al. 2011). 
BSc can be successfully used for managing environmental aspects of performance (Länsiluoto and Järvenpää 2010). Wynder (2010) opines that environmental performance can be recognised as a driver of financial performance. A BSc-based green-SC performance measurement approach is reported in Cheffi and Dey (2012). Relationship between sustainable BSc and eco-efficiency analysis is found in Möller and Schaltegger (2005). Ways to incorporate sustainable practices into BSc are reported in Butler et al. (2011). Instances prevail where environmental and social aspects are integrated with the organisational aspects of a company within a BSc framework (Figge et al. 2002).

The CDM approach framed in this article to assess green-SC performance of aUK-based manufacturing company seeks to answer the following research questions:

(i) How are green-SC constructs, sub-constructs and sub-sub constructs related according to strategic, tactical and operational levels of management and what are the implications of these for green-SC decision making?

(ii) What are the critical evaluating factors responsible for measuring green-SC performance?

(iii) How do the constructs, sub-constructs and sub-sub-constructs of an SC form a greennetwork?

(iv) How does a green causal relationship, comprising the green-network, serve as a blackbox for green-SC performance measurement?

(v) What are the elements that contribute to the GrBSc while measuring SC performance?

(vi) How are the collaborative opinions, in linguistic terms, of stakeholders of a manufacturing company considered in GrBSc? 
(vii) How is qualitative and vague information, in linguistic terms, of the stakeholders tackled in the inter-dependent network for measuring green-SC performance of the manufacturing firm?

This research extends the literature in the field of green-SC by developing a novel green-SC performance framework for a UK-based carpet manufacturing firm by devising a novel GrBSc approach through integration of holistic green-SC performance constructs and implementing a collaborative decision-making approach.

\section{Green Balanced Scorecard-based Framework}

The British carpet industry is striving to survive amidst several competitors in EU. One of the sustainable manufacturing goals in the British carpet sector is the inclusion of a green element in the production planning processes. The manufacturing company under consideration takes such "green" elements and its environmental and social responsibilities seriously. The company is committed to the long-term aims of sustainable development in all business activities. Green-SC management is central to the entire business as the product is intrinsically 'green'. Carpets are manufactured from renewable resources, viz., wool from grass-fed sheep. The products have extended lifecycles. The manufacturing plants continually strive to reduce their environmental footprint through training of the employees in regard to environmental awareness in sustainable communities. Further, the green-SC includes recycling process waste and finished carpet at the end of its life. The company contributes positively to the Leadership in Energy and Environmental Design (LEED) building certification criteria as a part of the recognition of its sustainability credentials. The company meets the stringent standards of the Carpet and Rug Institute Green Label Plus programme thereby contributing to a healthy indoor environment. 


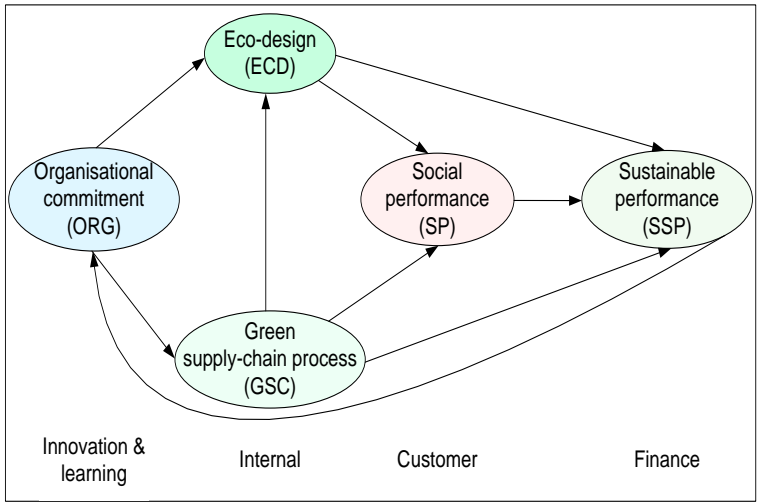

Fig. 1: The green causal relationship

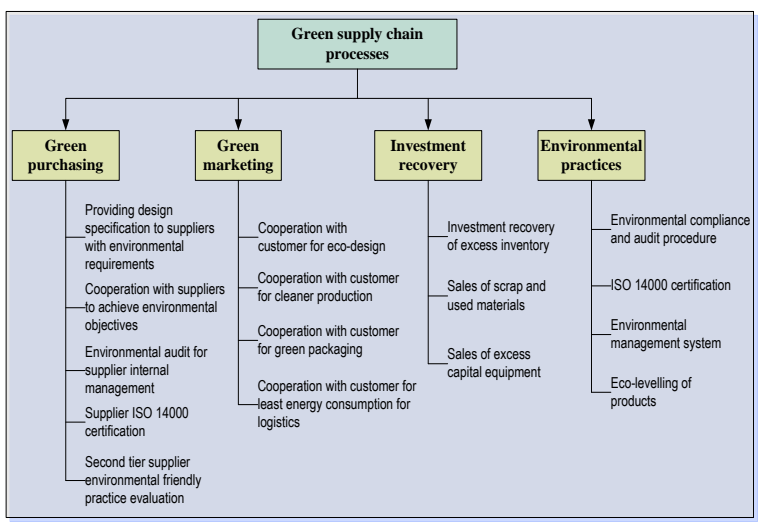

Fig. 3: Sub-constructs for 'green supplyperformance'

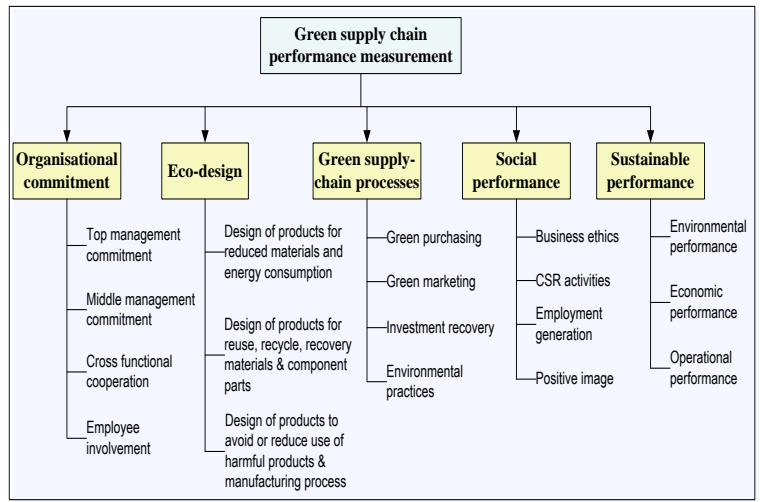

Fig. 2: Green supply-chain constructs

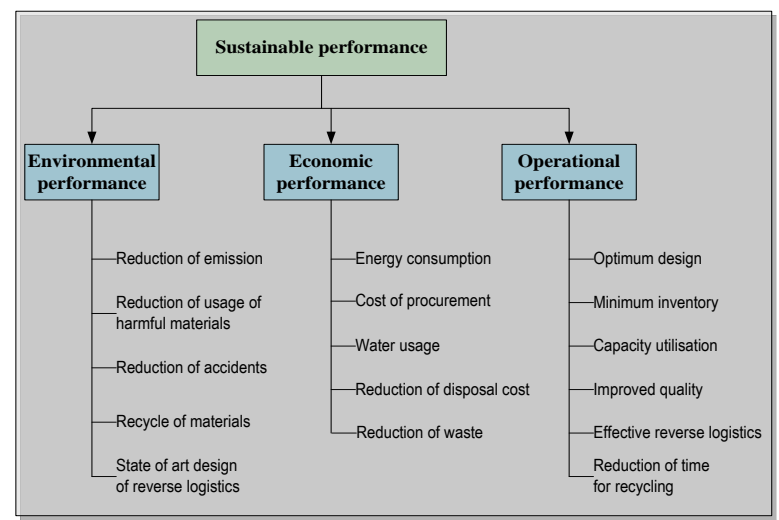

Fig. 4: Sub-constructs for 'sustainable chain processes'

The company utilises five constructs for their GrBSc-based SC framework. Three of these are leading and two are lagging. Organisational commitment, eco-design, and green-SC processes are considered as leading constructs while social and sustainable performances are treated as lagging constructs. Considering these five constructs a green-causal relationship is designed (Figure 1). These constructs contain sub-constructs and sub-sub-constructs as illustrated in Figures 2, 3 and 4. The sub-constructs and sub-sub-constructs considered for the green-SC performance measurement are collated from the reported studies (Dey and Cheffi 2012; Cheffi and Dey 2012; Hervani et al. 2005; Olugu et al. 2010; Rao 2002; Rao and Holt 2005; Tsoulfas and Pappis 2008; Thipparat 2011; Van Hoek 1999; Zhu et al. 2007a: Zhu et al. 2007b; Zhu et al. 2008). 


\subsection{Five-step procedure}

Both primary and secondary methods of data collection are administered in this research.

Some of the holistic constructs, sub-constructs and sub-sub-constructs for the green-SC performance approach are obtained from a detailed literature research. These constructs are collated to form a logical structure so as to develop a green-causal relationship (Fig. 1). A number of researchers in the arena of green-SC performance measurement are asked to comment on the proposed GrBSc based performance framework. Their opinions contribute to the CDM approach in building the GrBSc framework. A fuzzy-ANP approach is considered and a five-step procedure (Fig. 5) is followed to implement the GrBSc framework:

Step1: The collaborative decision-making approach gives rise to the importance
weights of the SC construct, sub construct and sub-sub-sub construct for GrBSc
framework. The scale for obtaining the importance weights are relied on Saaty's
nine point scale.
Step 2: The weights for these constructs, sub-construct and sub-sub constructs are
fuzzified using fuzzy mapping function.
Step 3: Based on the interdependencies of the constructs, sub-construct and sub-
sub constructs and the green casual relationship a network if formulated using
ANP. Three networks have been formulated - one is for all the constructs, another
is for the "green supply-chain processes" sub-construct and the third is
"sustainable performance" sub-construct.
Step 4: The normalised weights are computed based on the fuzzy ANP
framework.
Step 5: Global priorities are calculated. These global priorities indicate the
percentage contribution in SC performance of each of the elements in construct,
sub-construct and sub-sub constructs in within GrBSc framework.

Fig. 5: The five-step procedure for the implementation of GrBSc

\subsection{Collaborative decision-making through fuzzy-ANP}

ANP is a qualitative multi-attribute decision-making approach providing structured communication to address business problems. In this research ANP is used within the GrBSc framework as it provides a collaborative trade-off under the complexity of multi-criteria environment. ANP is a comprehensive decision-making method that elucidates the interdependencies, reflects the dependencies as quantitative outcome and simultaneously provides feedback within and between the clusters of elements (Ravi et al. 2005). Therefore, ANP focuses dependency within a set of elements, i.e., inner dependence, and among different sets of elements, i.e., outer dependence (Saaty 1996). The methodology has a non- 
linear structure dealing with sources, cycles and sinks while having a hierarchy of linear form, like AHP (Ravi et al. 2005). In this research the CDM approach works in two linked segments. One segment influences the dependencies of constructs, sub-constructs and subsub-constructs through building network while the other segment generates a network having control over all the elements and clusters.

Qualitative feedback is received from the collaborative group of the manufacturing company in terms of linguistic preferences which are then converted into importance weights using the CDM scale based on Saaty (1980) (Fig. 6). This feedback contains imprecise and vague information having conflicting-in-nature criteria with incommensurable units of measurement. Therefore, a structured way to process such imprecise and vague information is introduced using a triangular fuzzy membership function. Fuzzy sets are able to resemble human decisions. Further, fuzzy triangular numbers transform the qualitative linguistic preferences into quantitative forms.

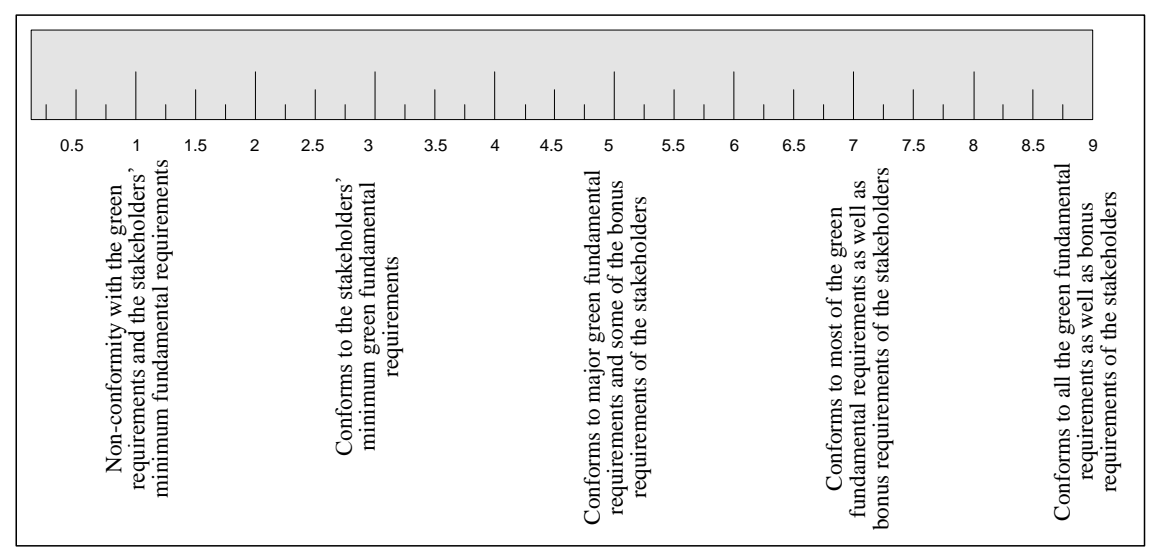

Fig. 6: Collaborative decision-making scale (adapted from Bhattacharya et al. 2010)

The fuzzy-ANP method presented in this paper is an extension of the fuzzy-AHP approach presented in Chan et al. (2008). This research adopts the process of obtaining the fuzzy numbers as elucidated in Chan et al. (2008). The identical notations are used as that of Chan et al. (2008) and these fuzzy numbers are infused into the ANP approach. A tilde ' $\sim$ ' on a letter is used to designate a fuzzy number. The triangular fuzzy number is represented by $N^{Q c}=$ 
$\left(\mathrm{n}_{\mathrm{p} 1}, \mathrm{n}_{\mathrm{p} 2}, \mathrm{n}_{\mathrm{p} 3}\right)$, where $\mathrm{n}_{\mathrm{p} 1}, \mathrm{n}_{\mathrm{p} 2}$ and $\mathrm{n}_{\mathrm{p} 3}$ refer to the smallest possible, the most promising and the largest possible preference weights for the ' $\mathrm{p}$ 'th row of a decision-matrix respectively.

The following fuzzy algebra has been adopted from Chan et al. (2008) in order to compute the triangular fuzzy numbers for the proposed fuzzy-ANP method:

$N_{o i}^{j}$ : The triangular fuzzy numbers (where $i=1,2, \ldots, n$ and $j=1,2, ., m$ )

$W$ : A non fuzzy-number known as priority weight

For $N_{1}=\left(n_{11}, n_{12}, n_{13}\right)$ and $N_{2}=\left(n_{21}, n_{22}, n_{23}\right)$, the ordinate of the intersecting point is calculated as $V\left(N_{2} \geq N_{1}\right)=\frac{n_{11}-n_{23}}{\left(n_{22}-n_{23}\right)-\left(n_{12}-n_{11}\right)}$.

In the matrix a comparison between $N_{1}$ and $N_{2}$ is required to be made to justify the judgemental values. In order to do so both the values of $V\left(N_{1} \geq N_{2}\right)$ and $V\left(N_{2} \geq N_{1}\right)$ are required to be computed.

Chan et al. (2008) defines the degree of possibility for a convex fuzzy number to be greater than ' $k$ ' convex fuzzy number $N_{i}$ (where $\left.i=1,2, \ldots, k\right)$ as:

$V\left(N \geq N_{1}, N_{2}, \ldots, N_{k}\right)=V\left[\left(N \geq N_{1}\right)\right.$ and $\left(N \geq N_{2}\right)$ and $\ldots$ and $\left.\left(N \geq N_{k}\right)\right]$

$=\min V\left(N \geq N_{1}\right), i=1,2, \ldots, k$.

Chan et al. (2008) further defines the weighted vector as:

$W_{P}=\left(m\left(P_{1}\right), m\left(P_{2}\right), \ldots, m\left(P_{n}\right)\right)^{T}$ where $P_{i}(i=1,2,3, \ldots ., n)$ are ' $n$ ' elements.

This relation of $W_{P}$ holds for $m\left(P_{i}\right)=\min V\left(N_{i} \geq N_{k}\right)$ (where $k=1,2, \ldots, n$ and $\left.k \neq i\right)$.

Normalisation of $W_{p}$ generates normalised weight vectors: 
$W=\left(w\left(P_{1}\right), w\left(P_{2}\right), \ldots, w\left(P_{n}\right)\right)^{T}$,

where $W$ is a non-fuzzy number that provides priority weights of one alternative over other.

\section{Case Study of a Manufacturing Industry}

The UK-based carpet manufacturing company has a stringent environmental policy reviewed through external audit. The company under consideration achieves all emissions and energy consumption targets of the regulators. There is no reverse logistic system in place for their products. There is no environmental performance measurement framework in practice for measuring carbon footprint, carbon offsetting etc. Further, the company does not use renewable energy.

The manufacturing company has a dedicated marketing team that remains in touch with its customers. Interviews revealed that there are several issues that need to be addressed in order to improve information integration with customers. These evolve mainly due to fast changing customer requirements. In addition, customers often change their requirements even after placing the orders. Moreover, there is evidence of order cancellation and delay in processing during production because of communication gaps. Hence, there remains room for improvements in information integration that may result in improvement to the overall green performance of the SC.

The company's environmental policy allows purchasing materials only from reliable and recognised suppliers, who can conform to the company's stringent environmental requirements. They have more than 300 suppliers ofwhich around 20 suppliers are strategic, i.e., with long-term relationship. The company's purchasing procedures are audited by the British Standard Institute as a part of the company's ISO 9002 certification process. All the 
chemicals used conform to $\mathrm{COSHH}$ regulations. The company has also initiated special agreements with suppliers to ensure that all containers and other materials brought on to the company's premises are either returned to the manufacturer for recycling or are disposed of by safe, secure and legal methods. The introduction of the ISO 14000 certification standard focuses attention on the environmental impact performance of the firm's processes. Purchase is one of the key processes, which is assessed in ISO 14000 because it is responsible for not only procurement of the materials but also their disposal at the end of their useful life.

\subsection{Collaborative decision-making}

Development of a set of green performance measurement constructs for GrBSc involves a complicated process and is challenging for businesses. Although in a typical firm a certain number of performance metrics is prevalent for assessing its financial performance, green-SC related performance metrics have not been widely adopted as businesses are typically uninformed of them. Firms often find that there is a lack of operational guidelines on how to develop performance measurement criteria and constructs (Lapide, 2000). Therefore, a group decision-making process assists in developing green-SC performance measurement metrics and criteria hierarchically across the cross-functional levels. Stakeholders of the carpet manufacturing firm are selected from the following departments: marketing, production, purchasing, information, projects and human resources. Six key actors are selected from each stakeholder for their participation in the interviews. The interviewees from each stakeholder comprise one person from manager, deputy manager and assistant manager levels and three key officers.

There are many decision points and variables within the company's decision-making processes. They are complex and need consideration of multiple factors and the involvement 
of various stakeholders. Although the decisions are currently being made with the involvement of concerned stakeholders, an appropriate collaborative decision-support system could help to standardise decision-making processes for making the right decision quickly. The company works closely in a coordinated manner with their strategic suppliers, viz., wool and jute manufacturers. They coordinate with their suppliers when making critical decisions with regard to materials specification, design option selection and production planning.

A focus group has been formed within the manufacturing company to consider decisionsupport aspects. This group comprises persons from each stakeholder, viz., marketing, production, purchasing, information, projects, and human resources. All members of the group have more than twenty years' experience in manufacturing and have at least five years' experience with the company. They have been briefed on the objectives (green-SC performance measurement). The green-SC performance method is then explained to them including the rationale for each construct and their inter-relationships. The fuzzy-ANP method is then elaborated in order to explain not only how the green-SC performance method is to be undertaken but also to allow them to understand its rationale for selection. Next, the participants are asked to compare pair-wise the high level constructs for deriving their importance. Subsequently, they also compare sub-constructs pair-wise. These comparisons are synthesised using the fuzzy-ANP framework to determine the importance of all the bottom level sub-constructs. Each functional manager is then asked to derive their green-SC performance against each bottom level sub-constructs.

The group forms a consensus decision in linguistic terms under the chairmanship of the operational director of the company. The process of decision-making is collaborative as flow and subsequent sharing of information is from one functional area to another. The procedures 
of performance measurement have been explained to the group within a workshop environment.

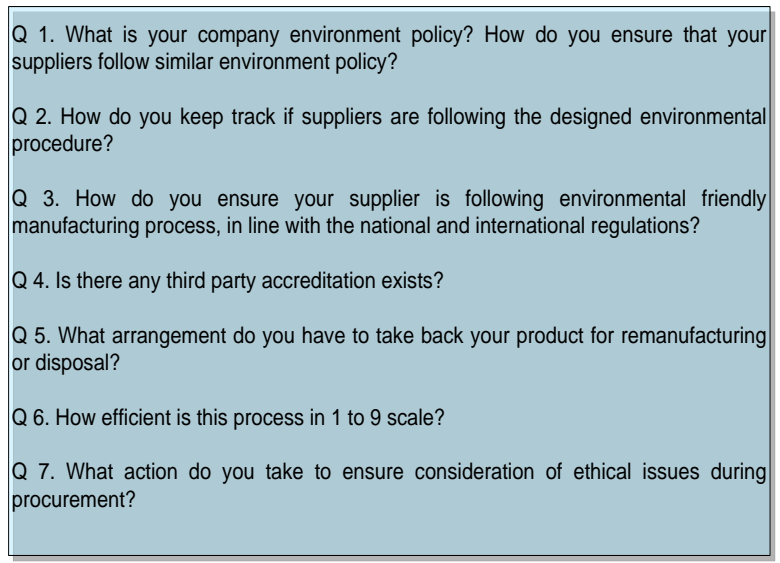

Fig. 7: Sample questionnaire on green purchasing strategy of the company

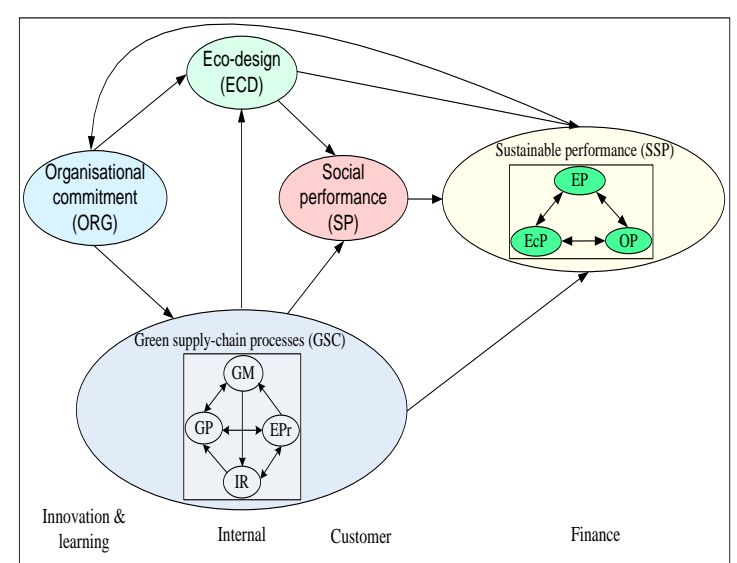

Fig. 8: Collaborative ANP network illustrating the causal relationship

A questionnaire-based survey (Fig. 7) is administered to the group. The responses are then collated and overall performance of the green-SC is derived using the fuzzy-ANP based BSc approach. The collaborative decision-making assists in obtaining a green causal relationship. The fuzzy-ANP assists in capturing the level of vagueness of the information contained in the outcome of the consensus CDM process. BSc is tabulated to assess the development of the green performance and its dependent elements in the causal relationship.

\subsubsection{Normalised weight for constructs and sub-constructs}

The performances of the elements of the green causal relationship (Fig. 1) are to be captured, viz., organisational commitment, ecological design, social performance, green-SC processes and sustainable performance. Considering the causal relationship an ANP network is formed (Fig. 8).

The linguistic preferences for the company are now obtained from the group and those qualitative preferences are translated into a quantitative meaning using fuzzy-ANP involving equations (1) to (5). Pair-wise comparison matrices are formed (Figs. A1 and A2 of 
Appendix) taking into consideration the sub-constructs embedded within each construct. Interdependencies of the constructs are established once the fuzzy quantitative measures for the linguistic preferences are obtained (Fig. A3 of Appendix).

Table 1: Super decision matrix

\begin{tabular}{ccccccc}
\hline & ORG & ECD & GSC & SP & SSP & Weight \\
\hline ORG & 0 & 0.7719 & 1 & 0 & 0 & 0.331 \\
ECD & 0 & 0 & 0 & 0.9124 & 0.4895 & 0.241 \\
GSC & 0 & 0.2281 & 0 & 0.0875 & 0.2106 & 0.102 \\
SP & 0 & 0 & 0 & 0 & 0.2997 & 0.075 \\
SSP & 1 & 0 & 0 & 0 & 0 & 0.250 \\
\hline
\end{tabular}

Super decision matrix (Table 1) using the ANP approach is constructed. It is to be noted that the decision-makers (i.e., the formed group in collaborative decision-making phase) have provided their level of importance on the constructs ORG, ECD, GSC, SP and SSP. These are found to be $25 \%, 17 \%, 20 \%, 13 \%$ and $25 \%$ respectively. The following realistic technique (Yüksel and Dağdeviren 2010) is considered to obtain the preference weights of the super decision matrix. This procedure is followed throughout this paper in order to compute the preference weights of the super decision matrices (Tables $2 \& 3$ ).

$$
\left[\begin{array}{ccccc}
0 & 0.7719 & 1 & 0 & 0 \\
0 & 0 & 0 & 0.9124 & 0.4895 \\
0 & 0.2281 & 0 & 0.0875 & 0.2106 \\
0 & 0 & 0 & 0 & 0.2997 \\
1 & 0 & 0 & 0 & 0
\end{array}\right] \times\left[\begin{array}{c}
0.25 \\
0.17 \\
0.20 \\
0.13 \\
0.25
\end{array}\right]=\left[\begin{array}{c}
0.331 \\
0.241 \\
0.103 \\
0.075 \\
0.250
\end{array}\right]
$$

The causal relationship among the elements of "green supply chain processes" is shown in Fig. 9. Four elements, viz., green purchasing, green marketing, environmental practices and investment recovery, are considered in order to build this relationship. A similar procedure is followed in order to obtain fuzzy decision matrices, interdependency matrices (Fig. A4 of Appendix) and super decision matrix (Table 2).

Table 2: Super decision matrix

\begin{tabular}{lccccc}
\hline & GP & GM & IR & EPr & Weight \\
\hline GP & 0.000 & 0.244 & 0.000 & 0.641 & 0.2882 \\
GM & 0.715 & 0.000 & 0.500 & 0.000 & 0.2930 \\
IR & 0.195 & 0.000 & 0.000 & 0.359 & 0.1962
\end{tabular}




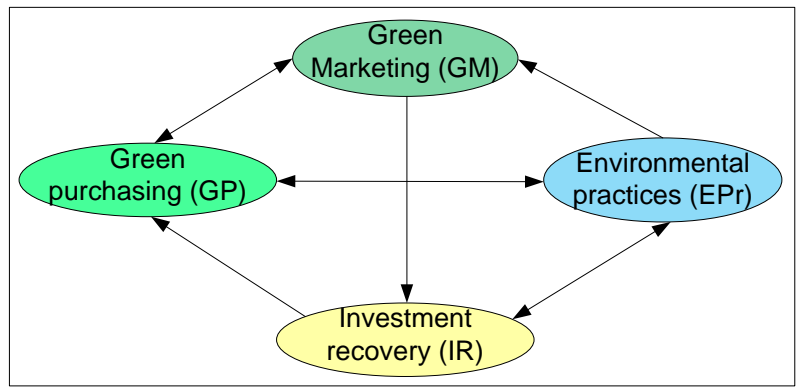

$\begin{array}{llllll}\mathbf{E P r} & 0.090 & 0.756 & 0.500 & 0.000 & 0.2226\end{array}$

Fig. 9: Relationship within 'green supply-chain process'

The causal relationship for a "sustainable performance" construct is built (Fig. 10). The subconstructs "environmental performance", "economic performance" and "operational performance" interact with each other and bind the relationship. Similar procedure is followed to obtain fuzzy decision matrices, interdependency matrices (Fig. A5 of Appendix) and super decision matrix (Table 3).

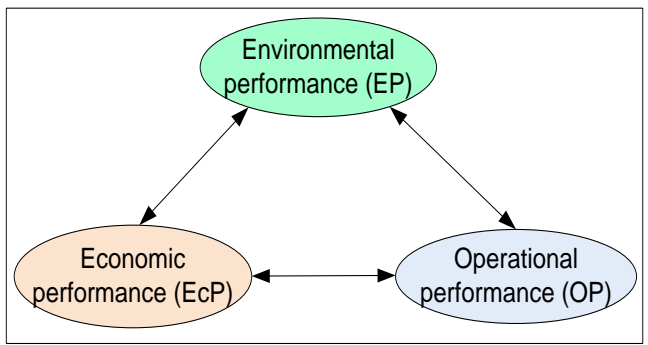

Table 3: Super decision matrix

\begin{tabular}{lcccc}
\hline & EP & EcP & OP & Weight \\
\hline EP & 0.000 & 0.359 & 0.595 & 0.351 \\
EcP & 0.756 & 0.000 & 0.405 & 0.330 \\
OP & 0.244 & 0.641 & 0.000 & 0.319 \\
\hline
\end{tabular}

Fig. 10: Relationship within sustainable performance

\section{Results and Discussion}

The preference weights obtained from the super decision matrices are processed so as to have global priority (GP) values. GPs are the performance measures for the SC constructs, subconstructs and sub-sub-constructs of the carpet manufacturing company. GPs are calculated by multiplying the normalised weight of constructs, sub-constructs and sub-sub-constructs. An example of the computational process is elucidated below (for "organisation commitment" construct),

$\mathrm{GP}=$ Weight of constructs $(O R G) \times$ Sub-constructs $($ top management commitment $)=0.331 \times 0.1667=0.055$. Similarly the remaining GPs are calculated and these are reflected in the green-BSc (Fig. 11).

From Fig. 11 the percentage contribution of the construct, sub-construct and sub-subconstruct responsible for evaluating the performance of the green-supply-chain is apparent. 


\begin{tabular}{|c|c|c|c|c|c|c|}
\hline Constructs & $\begin{array}{l}\text { Weight of } \\
\text { constructs }\end{array}$ & Sub-constructs & $\begin{array}{l}\text { Weight of sub. } \\
\text { constructs }\end{array}$ & Sub-sub-constructs & $\begin{array}{l}\text { Weight of sub } \\
\text { sub-criteria }\end{array}$ & $\begin{array}{l}\text { Global } \\
\text { priority }\end{array}$ \\
\hline \multirow{4}{*}{$\begin{array}{l}\text { Organisational } \\
\text { commitment }\end{array}$} & \multirow{4}{*}{0.331} & Top maragement commitment & 0.1667 & & & 0.0550 \\
\hline & & Middle management commitment & 0.4378 & & & 0.1450 \\
\hline & & Cross functional cooperation & 0.0041 & & & 0.0020 \\
\hline & & Employee involvement & 0.3914 & & & 0.1290 \\
\hline \multirow{3}{*}{ Eco-design } & \multirow{3}{*}{0.241} & $\begin{array}{l}\text { Design of products for reduced materia's } \\
\text { and energy corsumpion }\end{array}$ & 0.4823 & & & 0.1160 \\
\hline & & $\begin{array}{l}\text { Design of products for reuse, recycle, } \\
\text { recovery materials and componert parts }\end{array}$ & 0.1698 & & & 0.0410 \\
\hline & & $\begin{array}{l}\text { Design of products to avoid or reduce use } \\
\text { of harmful products and manufacturing } \\
\text { procass }\end{array}$ & 0.3479 & & & 0.0840 \\
\hline \multirow{16}{*}{$\begin{array}{l}\text { Green supply } \\
\text { chain } \\
\text { processes }\end{array}$} & \multirow{16}{*}{0.103} & Green purchasing & 0.2882 & $\begin{array}{l}\text { Providing design specificalion to } \\
\text { suppliers with environtental } \\
\text { requirements }\end{array}$ & 0.2864 & 0.0080 \\
\hline & & & & $\begin{array}{l}\text { Cooperation with suppliers to achieve } \\
\text { environmental objectives }\end{array}$ & 0.4178 & 0.0120 \\
\hline & & & & $\begin{array}{l}\text { Environmental audit for supplier } \\
\text { internal management }\end{array}$ & 0.0203 & 0.0008 \\
\hline & & & & Supplier ISO 14000 certification & 0.2495 & 0.0084 \\
\hline & & & & $\begin{array}{l}\text { Second tier supplier environmental } \\
\text { friendly practice evaluation }\end{array}$ & 0.0260 & 0.0008 \\
\hline & & Green marketing & 0.2930 & $\begin{array}{l}\text { Cooperation with customer for eco- } \\
\text { design }\end{array}$ & 0.1854 & 0.0050 \\
\hline & & & & $\begin{array}{l}\text { Cooperation with customer for } \\
\text { claaner production }\end{array}$ & $0.3 \uparrow 68$ & 0.0100 \\
\hline & & & & $\begin{array}{l}\text { Cooperation with customer for green } \\
\text { packaging }\end{array}$ & 0.3132 & 0.0100 \\
\hline & & & & $\begin{array}{l}\text { Cooperation with customer for least. } \\
\text { energy corsumption for logistics }\end{array}$ & 0.1848 & 0.0060 \\
\hline & & Investmant recovery & 0.1962 & Invest recovery of excess invertory & 0.2890 & 0.0060 \\
\hline & & & & Sales of scrap and used materials & 0.2904 & 0.0060 \\
\hline & & & & Salas of excass capital equiprent & 0.4208 & 0.0080 \\
\hline & & Environmental practicas & 0.2228 & $\begin{array}{l}\text { Environmental compliance and audit } \\
\text { procadure }\end{array}$ & 0.3778 & 0.0080 \\
\hline & & & & ISO 14000 certification & 0.5521 & 0.0120 \\
\hline & & & & Environmental management system & 0.0321 & 0.0008 \\
\hline & & & & Eco-levelling of products & 0.0382 & 0.0009 \\
\hline \multirow{4}{*}{$\begin{array}{l}\text { Social } \\
\text { performance }\end{array}$} & \multirow{4}{*}{0.075} & Business ethics & 0.4180 & & & 0.0340 \\
\hline & & CSR activities & 0.0840 & & & 0.0080 \\
\hline & & Employment gereration & 0.4160 & & & 0.0330 \\
\hline & & Positive irage & 0.0820 & & & \\
\hline \multirow{16}{*}{$\begin{array}{l}\text { Sustainable } \\
\text { performance }\end{array}$} & \multirow{16}{*}{0.250} & Environmental performance & 0.3510 & Reduction of eristion & 0.2515 & 0.0220 \\
\hline & & & & $\begin{array}{l}\text { Reduction of usage of harrful } \\
\text { materials }\end{array}$ & 0.3690 & 0.0320 \\
\hline & & & & Reduction of accidents & 0.0173 & 0.0015 \\
\hline & & & & Racycle of materials & 0.2175 & 0.0200 \\
\hline & & & & State of art design of reverse logistics & 0.1447 & 0.0120 \\
\hline & & Economic performance & 0.3300 & Energy consumption & 0.2443 & 0.0200 \\
\hline & & & & Cost of procurement & 0.1312 & 0.0110 \\
\hline & & & & Water usage & 0.1080 & 0.0090 \\
\hline & & & & Raduction of disposal cost & 0.4019 & 0.0330 \\
\hline & & & & Raduction of waste & 0.1146 & 0.0100 \\
\hline & & Operational performance & 0.3190 & Optimum design & 0.0564 & 0.0040 \\
\hline & & & & Minimum inventory & 0.0625 & 0.0060 \\
\hline & & & & Capacty utilisation & 0.0943 & 0.0070 \\
\hline & & & & Improved quality & 0.1073 & 0.0090 \\
\hline & & & & Effecfive reverse logistics & 0.1350 & 0.0100 \\
\hline & & & & Reduction of time for recycling & 0.5445 & 0.0430 \\
\hline
\end{tabular}

Fig. 11: Green balanced scorecard

Organisational commitment contributes $33.1 \%$ in the performance evaluation while ecodesign, green supply chain processes, sustainable performance and social performance 
contribute $24.1 \%, 10.3 \%, 25 \%$ and $7.5 \%$ respectively. This is illustrated in Fig. 12 . Contributions of the sub-constructs and sub-sub-constructs play a pivotal role in coming up with corrective measures for performance improvement. Figures 13 and 14 elucidate contribution of sub-constructs embedded within green-SC processes and sustainable performance.

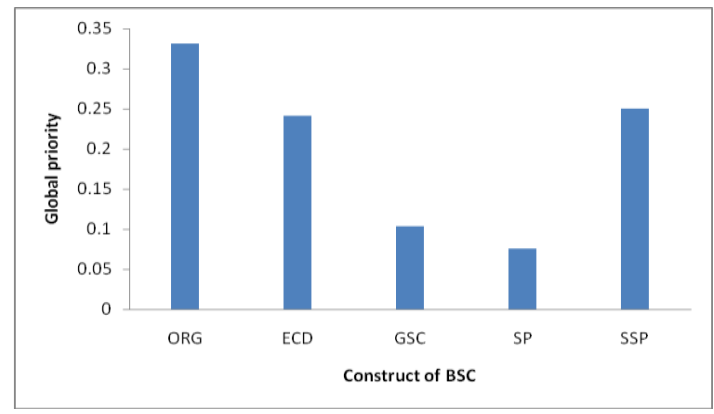

Fig. 12: Contribution of the SC-constructs

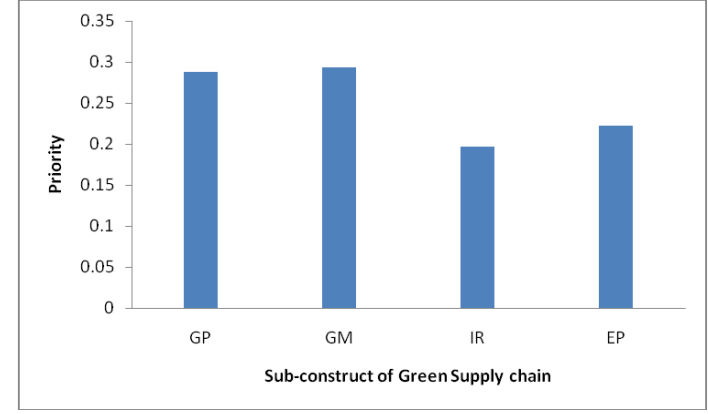

Fig. 13: Contribution of the subconstructs within green-SC processes

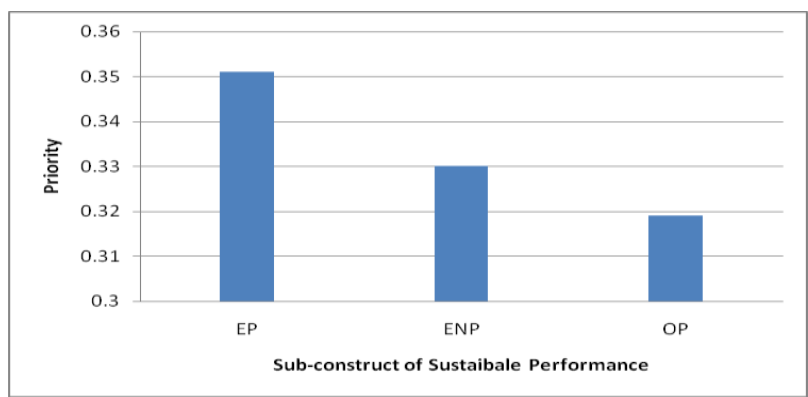

Fig. 14: Contribution of sub-constructs within sustainable performance

The group formed within the carpet manufacturing company have thoroughly reviewed the entire data and its analysis in order to validate the CDM approach. They are satisfied with the outcomes as they are able to measure green-SC performance of the organisation concerned and its supply-chain. The performance evaluation has suggested possible improvement measures that would improve the sustainability of the entire SC.

\section{Conclusions}

A green supply-chain performance measurement framework for a UK-based carpet manufacturing firm has been elucidated using an intra-organisational collaborative decisionmaking approach through a fuzzy-ANP based GrBSC framework. A green causal network is 
established involving organisational commitment, eco-design, green supply-chain process, social performance, and sustainable performance constructs. Sub-constructs and sub-subconstructs are identified and linked to the causal relationship. The performance measurement approach aids in making decisions of the manufacturing firm in regard to the overall organisational goals. The implemented approach assists the firm in identifying if it requires further collaborative data across the supply-chain. Collaborative decision-making plays a pivotal role in understanding the critical evaluating elements of performance measurement (Verdecho et al. 2009; Ulbrich et al. 2011; MacCarthy and Jayarathne 2012; Alfalla-Luque et al. 2012). The CDM based GrBSC approach assists managers in deciding if the suppliers' performances meet the industry and environment standards and the human resource is effective. The green SC performance measurement metrics and criteria are identified and developed using the group decision-making process across the cross-functional decisionmaking levels. The process of decision-making is collaborative as flow and subsequent sharing of information is from one functional area to another.

Holistic constructs of the firm are presented that cover the entire supply-chain network, i.e., upstream and downstream companies along with the focal organisation. Wynder (2010), while reporting a BSc framework with an emphasis on the relationships between leading and lagging performance measures, considers the impact of environmental performance by integrating environmental measures into the organisational strategy map. Thus, reactive and proactive subjective factors are considered in performance evaluation. The factors cover environmental, social, economic, and operational aspects of the SC. An analytical framework is adapted to measure green-SC performance involving all concerned stakeholders thereby aiding in decision-making in strategic, tactical and operational levels. 
The practical implication of this research is diverse. Managers of organisations would benefit in terms of decision-making performance and better managerial decision-making should result in improved company performance. Scope to analyse and benchmark an organisation's environmental initiatives across the entire supply-chain is indicated in this research. The empirical investigation into the UK-based carpet manufacturing company shows that internal operations play a pivotal role in assessing environmental performance. It has also been revealed that internal operations are dependent on suppliers' activities. The outcome of environmental initiatives and the level of integration of the SC may encourage managers to pay more attention to audit and performance thereby improving overall green-SC performance.

This empirical investigation into green-SC performance measurement determines the scope for further improvement between the company and suppliers in regard to collaborative information sharing, communication, eco-design and sustainable supply-chain performance. Further, the outcome of the investigation generates room for improvement in regard to supplier-customer-company relationship and various other improvement initiatives to achieve better green supply-chain performance of the company. The limitation of the study lies in the unscrupulous use of Saaty's nine-point scale in arriving at a pre-determined consensus opinion during the CDM process.

Although the company has stringent purchasing procedures there is no evidence that their suppliers have green environmental practices embedded in their manufacturing processes. Therefore, more emphasis should be placed on environmental issues by identifying and implementing key environmental indicators, viz., biodegradable product, environment friendly packaging, recycling. Further, the purchasing managers of the company feel that 
there is room for improvement in providing more technical support to suppliers. Future research could include implementation of the case with a more efficient CDM approach such as integrated fuzzy multi-criteria planning tool combining quality function deployment and ANP.

\section{References}

Alfalla-Luque, R., Medina-Lopez, C. and Dey, P.K., 2012. Supply chain integration framework using literature review. Production Planning \& Control: The Management of Operations, 1-18, iFirst.

Alfaro, J., Ortiz, A. and Poler, R., 2007. Performance measurement system for business processes. Production Planning \& Control: The Management of Operations, 18(8), 641-654.

Bai, C., Sarkis, J., Wei, X. and Koh, L., 2012. Evaluating ecological sustainable performance measures for supply chain management. Supply Chain Management: An International Journal, 17(1), 78-92.

Beamon, B.M., 1999. Designing the green supply chain. Logistics Information Management, 12(4), 332-342.

Bhagwat, R. and Sharma, M.K., 2009. An application of the integrated AHP-PGP model for performance measurement of supply chain management. Production Planning \& Control: The Management of Operations, 20(8), 678-690.

Bhattacharya, A., Geraghty, J. and Young, P., 2010. Supplier selection paradigm: An integrated hierarchical QFD methodology under multiple-criteria environment. Applied Soft Computing, 10(4), 1013-1027.

Björklund, M., Martinsen, U., Abrahamsson, M., 2012. Performance measurements in the greening of supply chains. Supply Chain Management: An International Journal, 17(1), 29-39.

Braam, G.J.M. and Nijssen, E.J., 2004. Performance effects of using the Balanced Scorecard: a note on the Dutch experience. Long Range Planning, 37(4), 335-349. 
Butler, J.B., Henderson, S.C. and Raiborn, C., 2011. Sustainability and the balanced scorecard: integrating green measures into business reporting. Management Accounting Quarterly, 12(2), 1-10.

Camarinha-Matos, L.M. and Abreu, A., 2007. Performance indicators for collaborative networks based on collaboration benefits. Production Planning \& Control: The Management of Operations, 18(7), 592-609.

Chan, F.T.S., Kumar, N., Tiwari, M.K., Lau, H.C.W. and Choy, K.L., 2008. Global supplier selection: a fuzzyAHP approach. International Journal of Production Research, 46(14), 3825-3857.

Cheffi, W. and Dey, P.K., 2012. Green supply chain performance measurement using balance scorecard in the manufacturing industry. In: T. Baines, B. Clegg, and D. Harrison (Eds.), Proceedings of the $10^{\text {th }}$ International Conference on Manufacturing Research, Vol. 2, pp. 811-817, 11-13 ${ }^{\text {th }}$ September, Birmingham.

Cohen, Y., 2011. A new technique for evaluating the balanced scorecard dashboard values. Problems and Perspectives in Management, 9(1), 78-84.

Cuthbertson, R. and Piotrowicz, W., 2008. Supply chain best practices - identification and categorisation of measures and benefits. International Journal of Productivity and Performance Management, 57(5), 389-404.

Dey, P.K. and Cheffi, W., 2012. Green supply chain performance measurement using the analytic hierarchy process: a comparative analysis of manufacturing organisations. Production Planning \& Control: The Management of Operations, iFirst, 1-19.

Figge, F., Hahn, T., Schaltegger, S. and Wagner, M., 2002. The sustainability balanced scorecard - linking sustainability management to business strategy. Business Strategy and the Environment, 11(5), 269-284.

Gunasekaran, A. and Cheng, T.C.E., 2008. Special Issue on logistics: new perspectives and challenges. Omega - The International Journal of Management Science, 36(4), 505-508. 
Gunasekaran, A. and Kobu, B., 2007. Performance measures and metrics in logistics and supply chain management: a review of recent literature (1995-2004) for research and applications. International Journal of Production Research, 45(12), 2819-2840.

Gunasekaran, A., Patel, C. and McGaughey, R.E., 2004. A framework for supply chain performance measurement. International Journal of Production Economics, 87(3), 333-347.

Hitchcock, T., 2012. Low carbon and green supply chains: the legal drivers and commercial pressures. Supply Chain Management: An International Journal, 17(1), 98-101.

Hervani, A.A., Helms, M.M. and Sarkis, J., 2005. Performance measurement for green supply chain management. Benchmarking: An International Journal, 12(4), 330-353.

Hofmann, E. and Locker, A., 2009. Value-based performance measurement in supply chains: a case study from the packaging industry. Production Planning \& Control: The Management of Operations, 20(1), 68-81.

van Hoek, R.I., 1999. From reversed logistics to green supply chains. Supply Chain Management: An International Journal, 4(3), $129-135$.

Hsu, C.-W., Hu, A.H., Chiou, C.-Y. and Chen, T.-C., 2011. Using the FDM and ANP to construct a sustainability balanced scorecard for the semiconductor industry. Expert Systems with Applications, 38(10), 12891-12899.

Hult, G.T.M., Ketchen Jr., D.J., Cavusgil, S.T. and Calantone, R.J., 2006. Knowledge as a strategic resource in supply chains. Journal of Operations Management, 24(5), 458-475.

Kaplan, R. S. and Norton, D. P., 1992. The balanced scorecard - measures that drive performance. Harvard Business Review, 70(1), 71-79. 
Kaplan, R.S. and Norton, D.P., 1996. The balanced scorecard: translating strategy into action. Boston: Harvard Business School Press.

Ketokivi, M. and Heikkilä, J., 2003. A strategic management system for manufacturing: linking action to performance. Production Planning \& Control: The Management of Operations, 14(6), 487-486.

Lapide, L., 2000. What about measuring supply chain performance? White paper, ASCET, 2 (15), 287-297, URL: http://ftp.gunadarma.ac.id/idkf/idkf-wireless/aplikasi/e-commerce/lapide.pdf, Accessed on 3 January 2013.

Länsiluoto, A. and Järvenpää, M., 2010. Greening the balanced scorecard. Business Horizons, 53(4), 385-395.

Lee, A.H.I., Chen, W.-C. and Chang, C.-J., 2008. A fuzzy AHP and BSC approach for evaluating performance of IT department in the manufacturing industry in Taiwan. Expert Systems with Applications, 34(1), 96-107.

Leung, L.C., Lam, K.C. and Cao, D., 2006. Implementing the balanced scorecard using the analytic hierarchy process \& the analytic network process. The Journal of the Operational Research Society, 57(6), 682-691.

MacCarthy, B.L. and Jayarathne, P.G.S.A., 2012. Sustainable collaborative supply networks in the international clothing industry: a comparative analysis of two retailers. Production Planning \& Control: The Management of Operations, 23(4), 252-268.

Malmi, T., 2001. Balanced scorecards in Finnish companies: A research note. Management Accounting Research, 12(2), 207-220.

Martinsons, M., Davison, R. and Tse, D., 1999. The balanced scorecard: a foundation for the strategic management of information systems. Decision Support Systems, 25(1), 71-88. 
Mendes, P., Santos, A.C., Perna, F. and Teixeira, M.R., 2012. The balanced scorecard as an integrated model applied to the Portuguese public service: a case study in the waste sector. Journal of Cleaner Production, 24 (March), 20-29.

Mettänen, P., 2005. Design and implementation of a performance measurement system for a research organization. Production Planning \& Control: The Management of Operations, 16(2), 178-188.

Möller, A. and Schaltegger, S., 2005. The sustainability balanced scorecard as a framework for eco-efficiency analysis. Journal of Industrial Ecology, 9(4), 73-83.

Olugu, E.-U., Wong, K.-Y. and Shaharoun, A.-M., 2010. Development of key performance measures for the automobile green supply chain. Resources Conservation and Recycling, 65(6), 567-579.

Rao, P., 2002. Greening the supply chain: a new initiative in South East Asia. International Journal of Operations \& Production Management, 22(6), 632 - 655.

Rao, P. and Holt, D., 2005. Do green supply chains lead to competitiveness and economic performance? International Journal of Operations \& Production Management, 25(9), 898-916.

Ravi, V., Shankar, R. and Tiwari, M.K., 2005. Analyzing alternatives in reverse logistics for end-of-life computers: ANP and balanced scorecard approach. Computers and Industrial Engineering, 48(2), 327-356.

Saaty, T. L., 1980. The analytic hierarchy process. New York: McGraw-Hill.

Saaty, T. L., 1996. Decision making with dependence and feedback: The analytic network process. Pittsburgh, PA: RWS Publications.

Sawalqa, F.A., Holloway, D. and Alam, M., 2011. Balanced scorecard implementation in Jordan. International Journal of Electronic Business Management, 9(3), 196-210. 
Shi, V.G., Koh, S.C.L., Baldwin, J. and Cucchiella, F., 2012. Natural resource based green supply chain management. Supply Chain Management: An International Journal, 17(1), 54-67.

Stwart, R.A. and Mohamed, S., 2001. Utilizing the balanced scorecard for IT/IS performance evaluation in construction. Construction Innovation, 1(3), 147-163.

Thakkar, J., Deshmukh, S.G., Gupta, A.D. and Shankar, R., 2006. Development of a balanced scorecard: an integrated approach of Interpretive Structural Modeling (ISM) and Analytic Network Process (ANP). International Journal of Productivity and Performance Management, 56(1), 25-59.

Tseng, M.-L., 2010. Implementation and performance evaluation using the fuzzy network balanced scorecard. Computers \& Education, 55(1), 188-201.

Tsoulfas, G. and Pappis, C., 2008. A model for supply chains environmental performance analysis and decision making. Journal of Cleaner Production, 16(15), 1647-1657.

Ulbrich, S., Troitzsch, H., van den Anker, F., Plüss, A. and Huber, C., 2011. How teams in networked organisations develop collaborative capability: processes, critical incidents and success factors. Production Planning \& Control: The Management of Operations, 22(5-6), 488-500.

Verdecho, M.J., Alfaro, J.J. and Rodriguez-Rodriguez, R., 2009. Foundations for collaborative performance measurement. Production Planning \& Control: The Management of Operations, 20(3), 193-205.

Wu, H.-Y., Tzeng, G.-H. and Chen, Y.-H., 2009. A fuzzy MCDM approach for evaluating banking performance based on Balanced Scorecard. Expert Systems with Applications, 36(6), 10135-10147.

Wynder, M., 2010. Chemico: Evaluating performance based on the Balanced Scorecard. Journal of Accounting Education, 28(3-4), 221-236. 
Yang, J., 2011. A structural model of supply chain performance in an emerging economy. International Journal of Production Research, iFirst, 1-9.

Yuan, F.-C. and Chiu, C., 2009. A hierarchical design of case-based reasoning in the balanced scorecard application. Expert Systems with Applications, 36(1), 333-342.

Yüksel, İ. and Dağdeviren, M., 2010. Using the fuzzy analytic network process (ANP) for Balanced Scorecard (BSC): A case study for a manufacturing firm. Expert Systems with Applications, 37(2), 1270-1278.

Zhu, Q., Sarkis, J. and Lai, K.-h., 2007a. Green supply chain management: pressures, practices and performance within the Chinese automobile industry. Journal of Cleaner Production, 15(11-12), 1041-1052.

Zhu, Q., Sarkis, J. and Lai, K.-h., 2007b. Initiatives and outcomes of green supply chain management implementation by Chinese manufacturers. Journal of Environmental Management, 85(1), 179-189.

Zhu, Q., Sarkis, J. and Lai, K.-h., 2008. Confirmation of a measurement model for green supply chain management practices implementation. International Journal of Production Economics, 111(2), 261-273. 


\section{Appendix}

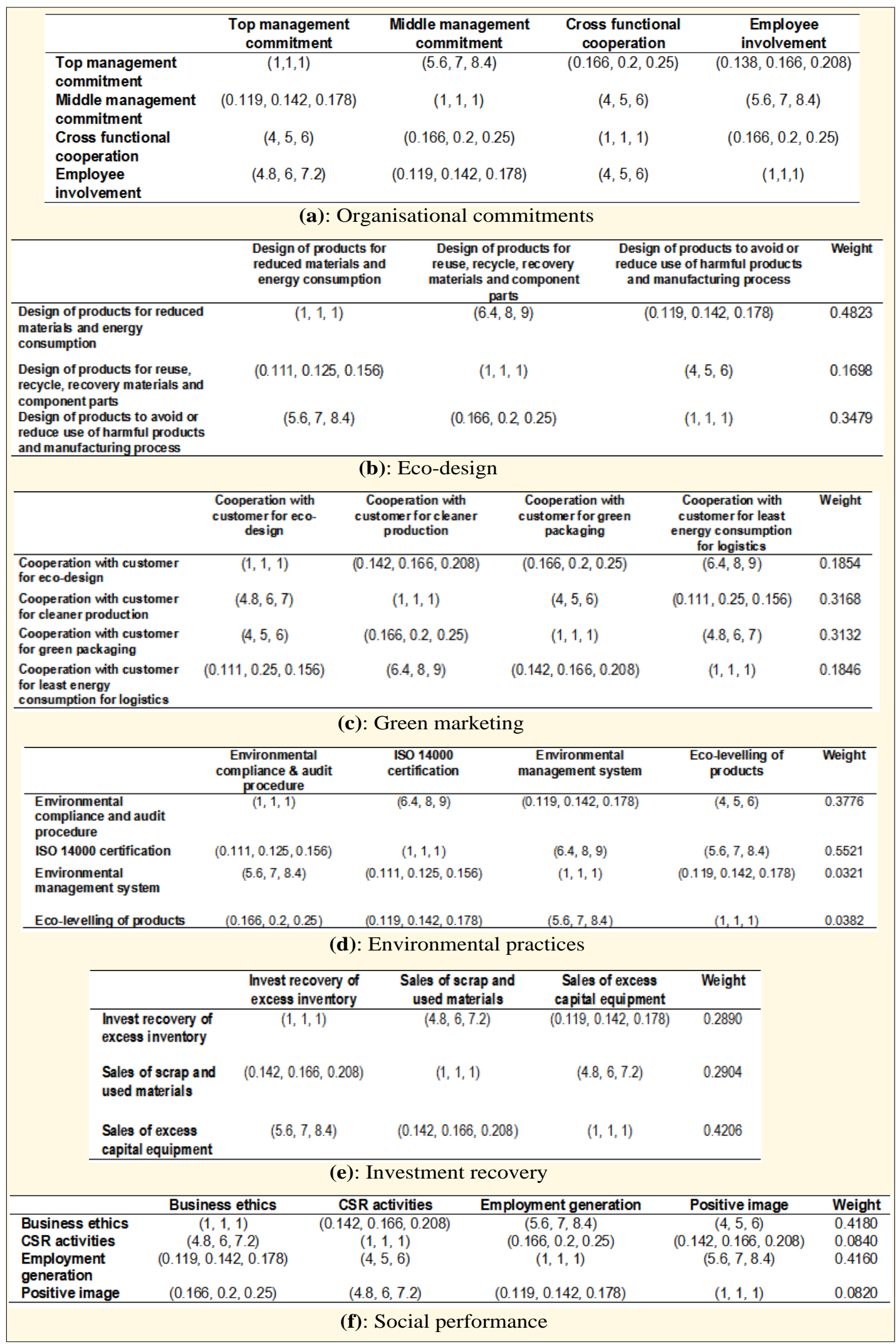

Fig. A1: Pair-wise comparison matrices 


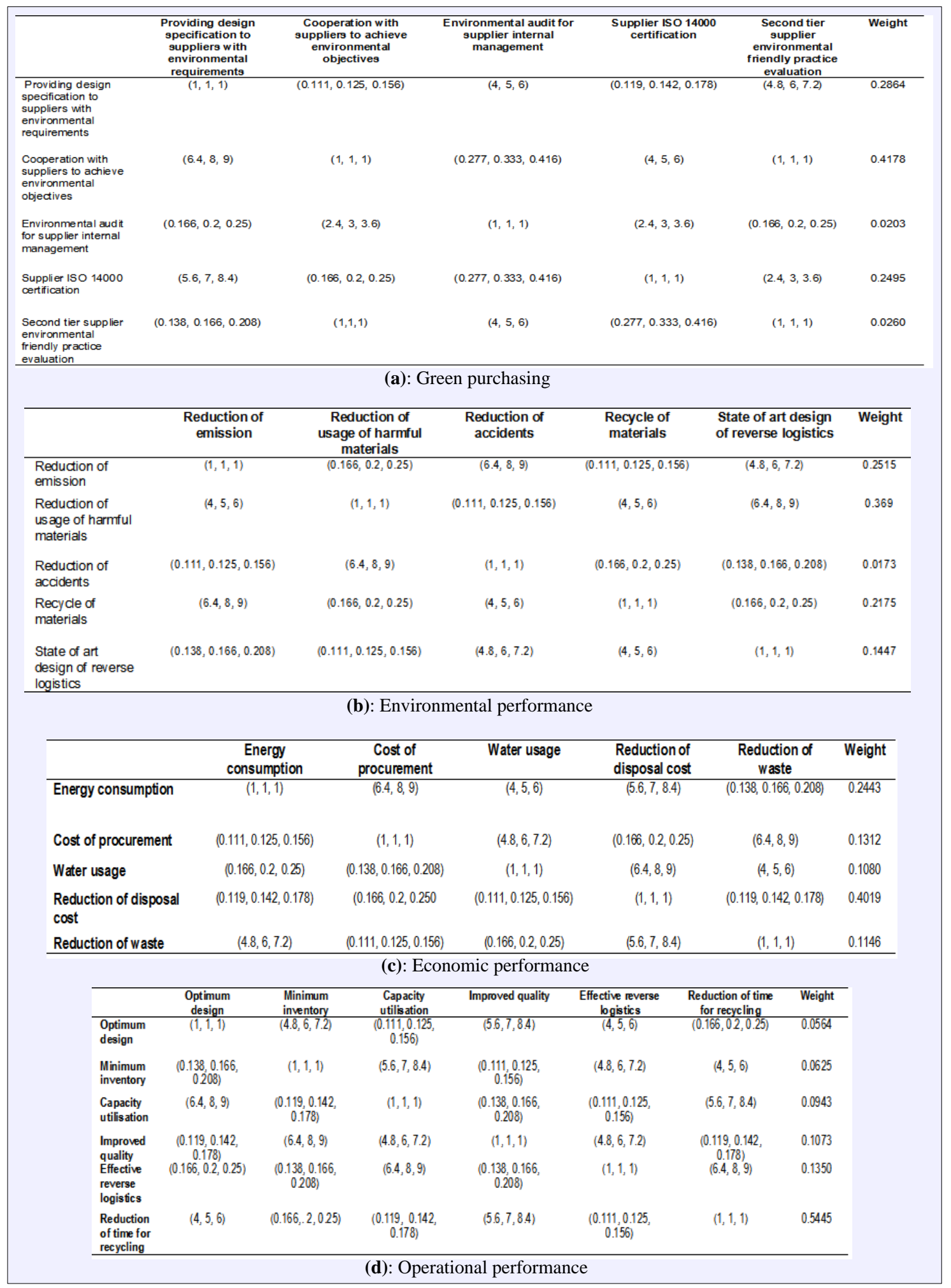

Fig. A2: Pair-wise comparison matrices 


\begin{tabular}{llll}
\hline & ORG & GSC & Weight \\
\hline ORG & $(1,1,1)$ & $(1,1.5,2)$ & 0.7719 \\
GSC & $(0.5,0.666,1)$ & $(1,1,1)$ & 0.2281 \\
\hline
\end{tabular}

(a): Interdependency matrix with respect to ECD

\begin{tabular}{cccc}
\hline & ECD & GSC & Weight \\
\hline ECD & $(1,1,1)$ & $(1.5,2,2.5)$ & 0.9124 \\
& & & \\
GSC & $(0.4,0.5,0.666)$ & $(1,1,1)$ & 0.0876 \\
\hline
\end{tabular}

(b): Interdependency matrix with respect to SP

\begin{tabular}{ccccc}
\hline & ECD & $\mathbf{S}$ & GSC & W eight \\
\hline ECD & $(1,1,1)$ & $(0.5,1,1.5)$ & $(1.5,2,2.5)$ & 0.4895 \\
SP & $(0.666,1,2)$ & $(1,1,1)$ & $(0.666,1,1.5)$ & 0.2998 \\
GSC & $(0.4,0.5,0.666)$ & $(0.666,1,1.5)$ & $(1,1,1)$ & 0.2107 \\
\hline \multicolumn{4}{c}{ (c): Interdependency matrix with respect to SSP }
\end{tabular}

Fig. A3: Interdependency matrices

\begin{tabular}{ccccc}
\hline & GM & IR & EPr & Weight \\
\hline GM & $(1,1,1)$ & $(1,1.5,2)$ & $(2,2.5,3)$ & 0.715 \\
$\mathbf{R}$ & $(0.5,0.666,1)$ & $(1,1,1)$ & $(0.666,1,2)$ & 0.195 \\
$\mathbf{E P r}$ & $(0.333,0.4,0.5)$ & $(0.5,1,1.5)$ & $(1,1,1)$ & 0.09 \\
\hline
\end{tabular}

(a): Interdependency matrix with respect to GP

\begin{tabular}{lccc}
\hline & GP & EPr & Weight \\
\hline GP & $(1,1,1)$ & $(0.333,0.4,0.5)$ & 0.244 \\
EPr & $(2,2.5,3)$ & $(1,1,1)$ & 0.756 \\
\hline
\end{tabular}

(c): Interdependency matrix with respect to GM

\begin{tabular}{cccc}
\hline & GM & EPr & Weight \\
\hline GM & $(1,1,1)$ & $(0.666,1,1.5)$ & 0.5 \\
EPr & $(0.666,1,1.5)$ & $(1,1,1)$ & 0.5 \\
\hline
\end{tabular}

(b): Interdependency matrix with respect to IR

\begin{tabular}{cccc}
\hline & GP & IR & Weight \\
\hline GP & $(1,1,1)$ & $(3,3.5,4)$ & 0.641 \\
IR & $(0.25,0.285,0.333)$ & $(1,1,1)$ & 0.359 \\
\hline
\end{tabular}

(d): Interdependency matrix with respect to EPr

Fig. A4: Interdependency matrices

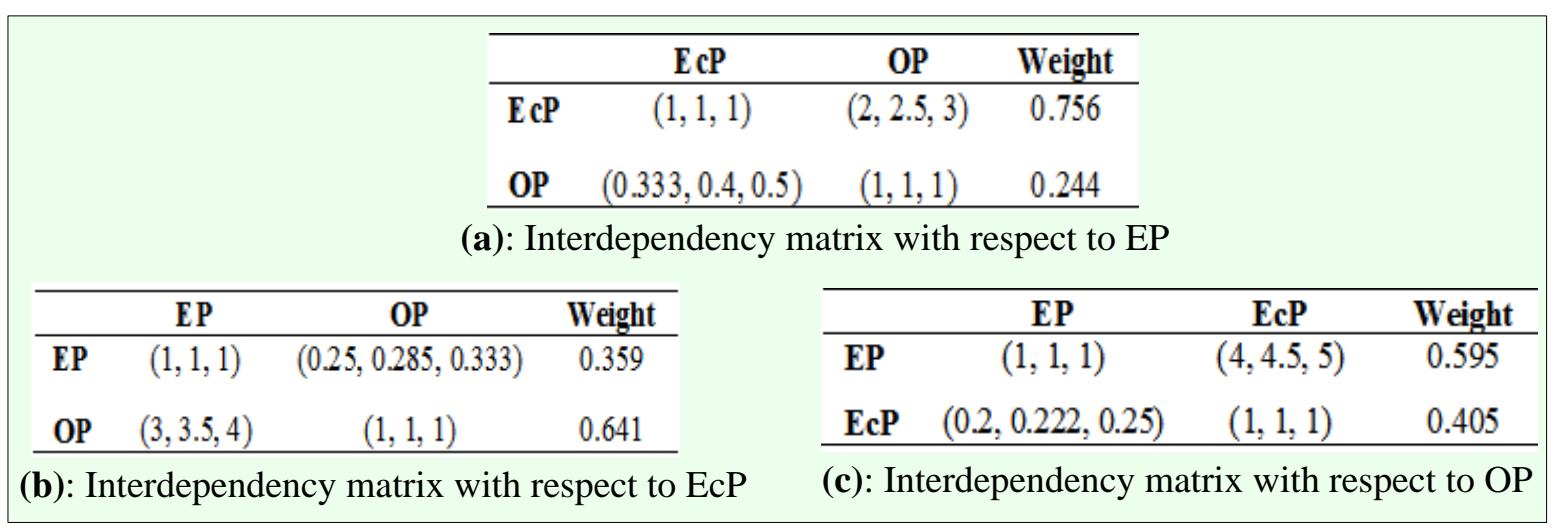

Fig. A5: Interdependency matrices 